\title{
O PROGRAMA SAÚDE NA ESCOLA E A CRIAÇÃO DE FERRAMENTA PARA APOIO ÀS AÇÕES DE PREVENÇÃO DE IST/AIDS: UMA REVISÃO DE LITERATURA
}

\author{
Maurício Durval de Sá1 \\ Zionel Santana ${ }^{2}$
}

RESUMO: O Programa Saúde na Escola é uma política intersetorial que tem atuação da Educação e Saúde, com a finalidade de prestar atenção integral à saúde da criança, adolescente, jovem e adulto da educação básica Brasileira. A utilização da escola como multiplicador de conhecimento é necessária para a realização de práticas de promoção a saúde, ações de prevenção e educação em saúde. Este trabalho tem como objeto identificar a aplicabilidade e as formas de abordagem da ação dos IST/ADS junto aos adolescentes que cursam o ensino médio, utilizando estudos originais, sendo utilizado o levantamento bibliográfico através SciELO (Scientific Eletronic Library Online), LILACS (Literatura LatinoAmericana e do Caribe em Ciências da Saúde) e BVS Ministério da Saúde. Os descritores utilizados foram: "Programa Saúde na Escola", "IST/AIDS" e "Prevenção" (LOBIONDOWOOD et al., 200I) ao qual foram lidos, agrupados e selecionados para compor o presente estudo, levando em consideração os descritores presentes durante a análise do conteúdo possibilitando, que há uma necessidade de mais estudos que abordem o Programa Saúde na Escola como um potencializador na prevenção das IST/AIDS, acreditando que assuntos nessa área contribuem para minimização das doenças e melhoria da aplicabilidade da ação ampliando assim discussões importantes entre educadores e educandos.

Palavras-chave: Sexualidade. Educação. Prevenção. Intersetorialidade.

\section{INTRODUÇÃO}

A escola é considerada um ambiente de multiplicação de conhecimento e importante espaço para a realização de práticas de promoção a saúde, ações de prevenção e educação em saúde. Atualmente é identificado através das políticas em saúde que existe um reconhecimento por parte do Ministério da Saúde e do Ministério da Educação, a necessidade de investimento em educação em saúde dentro da escola.

No Brasil, conforme Carvalho (2015, p. 1210) as ações educativas em saúde para escolares são de extrema importância nas ações de prevenção e promoção da saúde e

\footnotetext{
${ }^{\mathrm{I}}$ Discente do Curso de Mestrado Profissional Gestão Planejamento e Ensino da Universidade Vale do Rio Verde. E-mail: mauspu@gmail.com

${ }^{2}$ Orientado. Doutor e docente do curso de Mestrado em Gestão, Planejamento e Ensino na Universidade Vale do Rio Verde. E-mail: zionel@unincor.edu.br
} 
estiveram presentes nos discursos oficiais a partir de 1889 , época da Primeira República, centradas no ensino de comportamentos e hábitos considerados saudáveis.

O programa Saúde na Escola (PSE) é uma política intersetorial que tem atuação da Educação e Saúde, foi instituído pelo Decreto Presidencial n6.286, de 5 de dezembro 2007, com a finalidade de prestar atenção integral à saúde, de acordo com Costa, Figueiredo e Riberio (2013) o programa fortalece as ações da saúde no desenvolvimento de temáticas mudando a metodologia de atuação dos profissionais de ensino e os profissionais da saúde. As ações do PSE fortalecem o desenvolvimento da cidadania e qualidade educação em saúde das crianças, adolescentes, jovens e adultos que faz parte da educação publica brasileira.

A articulação entre Escola e Rede de Atenção Básica á Saúde é o eixo principal do programa, pois através dessa interligação que é possível fortalecer a qualidade do ensino em saúde para os educandos matriculados nas escolas que possuem adesão ao Programa Saúde na Escola.

O programa traz em sua estrutura como principal objetivo fortalecer "noções como “somar esforços", unir-se" e "articular-se" [...] propor modos de fazer educação e(m) saúde que demandam adaptabilidade, multifuncionalidade, flexibilidade e disposição." (SILVEIRA, MEYER e FÉLIX, 2019).

O programa saúde na escola trabalha com doze (I2) ações principais, sendo elas: I. Ações de combate ao mosquito Aedes aegypti;

2. Promoção das práticas corporais, da atividade física e do lazer nas escolas;

3. Prevenção ao uso de álcool, tabaco, crack e outras drogas;

4. Promoção da cultura de paz, cidadania e direitos humanos;

5. Prevenção das violências e dos acidentes;

6. Identificação de educandos com possíveis sinais de agravos de doenças em eliminação;

7. Promoção e avaliação de saúde bucal e aplicação tópica de flúor;

8. Verificação e atualização da situação vacinal;

9. Promoção da alimentação saudável e prevenção da obesidade infantil;

ıo. Promoção da saúde auditiva e identificação de educandos com possíveis sinais de alteração.

II. Direito sexual e reprodutivo e prevenção de DST/AIDS; e

12. Promoção da saúde ocular e identificação de educandos com possíveis sinais de alteração. 
Com a pandemia pelo novo Coronavírus, a ação de prevenção à Covid-ı9 passa a fazer parte dos temas discutidos no PSE, a partir da publicação da Portaria I88, 3 de fevereiro de 2020 que "Declara Emergência em Saúde Pública de importância Nacional (ESPIN) em decorrência da Infecção Humana pelo novo Coronavírus (2019-nCoV).”

Pode-se destacar que o Programa Saúde na Escola traz como eixos temáticos as prioridades de saúde e os problemas do dia-a-dia na sociedade principalmente pontos importantes como o debate sobre as "IST/AID”, para Alavarse e Carvalho (2006, p. 409), os adolescentes são contestadores e curiosos com a necessidade de ampliar a forma de ver e sentir, portanto, mais expostos aos comportamentos de risco, com essa nova necessidade de conhecer o mundo.

A discussão com o adolescente sobre sexualidade deve iniciar dentro de casa com os pais e se estender para a área escolar, com matérias especifica sobre esse tema, abordoando as mudanças fisiológicas, a sexualidade e educação sexual. Apesar da importância de discutir esse tema no contexto escolar, é observada uma dificuldade pelos professores em abordar, pois está relacionado à como o docente encara a temática, sendo considerado ainda um tabu. Outra questão que pode dificultar essa abordagem é a influência religiosa. (BARBOSA; FOLMER;2019)

É necessário que haja uma nova forma de atuação dos profissionais de educação, conforme Carvalho (1998, p. 248), sendo necessário e importante à recuperação da essência do ser, estimular e favorecer a relação com a vida e com o outro e tudo que emana dele mais para que isso seja alcançado necessariamente exige o esforço e a atenção para os aspectos filosóficos, políticos, sociais, culturais e até de poder contextualizar a comunidade.

Ressaltasse-se que o estudo tem como objetivo identificar a aplicabilidade e as formas de abordagem da ação IST/AIDS que compões o quadro de ações do Programa Saúde na Escola, junto aos adolescentes que cursam o ensino médio, uma vez que é possível identificar grandes dificuldades para a abordagem do tema pela sensibilidade do mesmo.

Pode-se, ainda, frisar que o estudo traz como hipóteses a dificuldade de abordagem do tema IST/AIDS nas escolas devido a falta de conteúdo didáticos e estudos que fornecem métodos de aplicabilidade junto aos educandos, dificultando assim o processo de discussão relacionados a está temática de grande relevância para os jovens e adolescentes. 
Para que seja fundamentado o presente estudo foi realizado um pesquisa nos bancos de dados disponíveis ao qual foi utilizado 47 artigos que incluírem no processo de construção do mesmo fatos relevantes abordando o Programa Saúde na Escola, IST/AIDS e métodos de prevenção.

Por fim, este estudo tem como objetivo identificar as dificuldades para a discussão do tema "IST/AIDS" a partir dos desafios encontrados pelos gestores e professores de biologia em abordar o tema junto aos educandos do ensino médio, sendo necessário conforme Cord et al (2015, p. 44), conhecer os profissionais e as dificuldades encontradas na execução e inserção do programa saúde na escola no cotidiano da vida academia, levando em consideração o formato de atuação e os encaminhamentos que surgem ao início das atividades.

\section{METODOLOGIA DA PESQUISA}

O referencial teórico foi elaborado com o intuito de situar o leitor acerca do tema abordado na pesquisa, contendo: a implantação do Programa Saúde na Escola, o trabalho com as IST's como ação do PSE - Programa Saúde na Escola, os tipos de Doenças Sexualmente Transmissíveis e as Infecções sexualmente transmissíveis - IST na adolescência, breve histórico sobre o vírus HIV na adolescência e sua diferença com relação à AIDS, o papel da educação e as ações de prevenção das IST, o papel dos gestores no PSE e o compromisso com a saúde e a relação do Programa com a comunidade escolar e com a Saúde.

Para tanto, esta parte do estudo foi totalmente construída utilizando-se a técnica de pesquisa bibliográfica, que consiste em realizar o estudo com base “[...] em material já elaborado, constituído principalmente de livros e artigos científicos” (GIL, 2002, p. 44), e foram utilizados neste pequeno levantamento vários artigos do âmbito da saúde e documentos ofertados pelo Ministério da Educação.

A busca pelos artigos aconteceu em sites de busca científica como o google acadêmico, e a escolha respeitou aqueles com maior destaque e relevância, ou seja, maior número de vezes citados em outros estudos, além de garantir que estudos mais recentes fossem também abordados. Todos os artigos foram lidos na íntegra, buscando neles informações a respeito dos temas tratados no referencial teórico, que sustentou a elaboração do Produto Técnico tecnológico deste estudo, uma cartilha capaz de subsidiar o trabalho dos profissionais da 
educação com relação ao desenvolvimento de ações do PSE, especificamente com relação às ISTs, HIV/ AIDS.

Trata-se de um estudo baseado em revisão narrativa de literatura de abordagem qualitativa, sendo utilizado as bases de dados eletrônicos SciELO (Scientific Eletronic Library Online), LILACS (Literatura Latino-Americana e do Caribe em Ciências da Saúde) e BVS Ministério da Saúde. Os descritores utilizados foram: "IST/AIDS”, "Programa Saúde na Escola" e "Prevenção" (LOBIONDO-WOOD et al., 20oI).

Os critérios de inclusão foram a partir da seleção de publicações de artigos sobre a temática dos anos de 1998 a 2021, no idioma português e espanhol, disponíveis na íntegra. Os critérios de exclusão foram todos os artigos que não enquadravam ao Programa Saúde na Escola, infecções sexualmente transmissíveis ou prevenção, sendo assim identificados e eliminados após a leitura do título e/ou resumos.

Procedeu-se a leitura de 63 artigos distribuídos entre as bases de dados. Após a leitura do título e/ ou resumo observou-se que alguns artigos não se enquadravam no tema proposto, sendo assim excluídos da seleção de artigos. Dentre esses 63 artigos, foram excluídos i6 artigos, visto que não se enquadravam com o tema Programa Saúde na Escola, IST/AIDS ou Prevenção. Ao finalizar a leitura foram selecionados 46 artigos que se enquadravam nos critérios proposto e que foram lidos na íntegra, conforme apresentado na Tabela $\mathrm{I}$.

Tabela I- Busca nos artigos das Bases de dados

Base de Dados

SciELO

LILACS

BVS Ministério da Saúde

Livro

Total
Artigos

$\begin{array}{cc}\text { Total } & \text { Utilizados } \\ 45 & 39 \\ 9 & \text { I } \\ 8 & 6 \\ \text { I } & \text { I } \\ 63 & 47\end{array}$

Para facilitar a compreensão, optou-se por abordar os temas de saúde na escola, as IST’s como ação do PSE - Programa Saúde na Escola, as DST - Doenças Sexualmente Transmissíveis e as Infecções sexualmente transmissíveis, a IST na adolescência, o HIV na adolescência, o papel da educação e as ações de prevenção, o papel dos Gestores e a saúde pública e a comunidade Escolar e a Saúde. 


\section{A implantação do Programa Saúde na Escola}

Em instituições escolares de Educação Básica, dentro os programas que visam desenvolver estratégias de promoção à saúde, destaca-se o Programa Saúde na Escola (PSE), que tem por objetivo melhorar a qualidade de vida dos estudantes, estando desde 2007 articulado e integrado ao programa Estratégia Saúde da Família (CAVALCANTI, LUCENA, LUCENA, 2015).

O Programa Saúde na Escola (PSE) caracteriza-se por um programa didáticopedagógico, delineado e divulgado no Brasil, pelo Ministério da Educação (MEC) em parceria com o Ministério da Saúde. Segundo Santos e Mezzaroba (2013), este programa relacionado à prevenção da saúde pode vir a impactar positivamente não somente os estudantes, bem como suas famílias, a comunidade escolar e a sociedade de seu entorno, a depender da forma como for aplicado e da dimensão crítico-reflexiva adotada.

Como dito, o PSE é resultado de uma parceria entre MEC e Ministério da Saúde, instituído pelo Decreto Presidencial n ${ }^{\circ} 6.286$, de os de dezembro de 2007. O programa objetiva fortalecer ações relacionadas à prevenção e promoção da saúde em linhas temáticas variadas por meio de uma nova política pública. Conforme mostrado na figura abaixo, podemos avaliar o arcabouço jurídico do PSE.

Figura I - Arcabouço jurídico do PSE - Programa Saúde na Escola

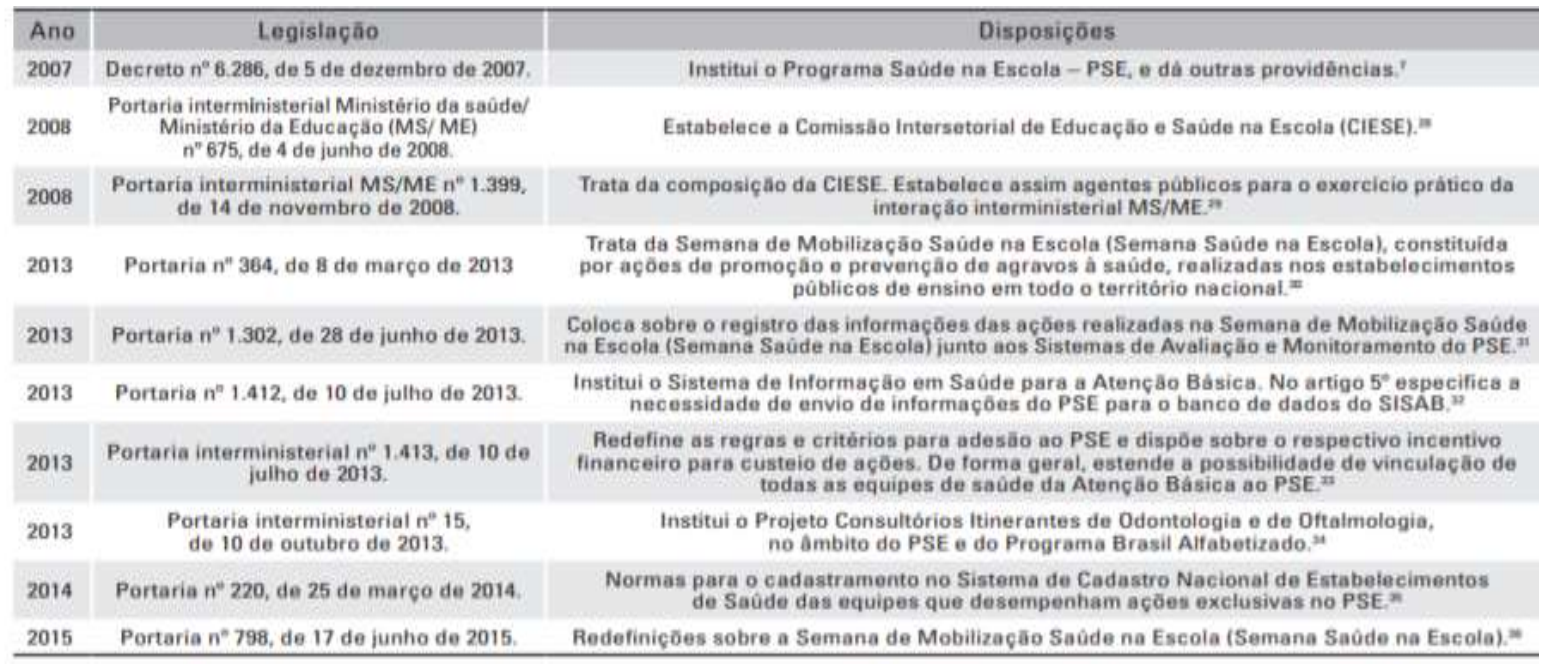

Fonte: (vieira, saporetti, belisário, 2016)

A escola, vista como um ambiente propício para o desenvolvimento pleno dos estudantes, possibilitando o exercício da cidadania e mudança de hábitos com vistas a uma 
vida mais saudável e ética, faz com que o PSE constitua-se como um “[...] importante espaço e uma oportunidade para discutir, conceituar, aprender, desenvolver e fazer crescer o ideário da Promoção da Saúde [...]” (LOPES, NOGUEIRA, ROCHA, 2oı8, p. 785).

Nesse sentido, de acordo com Farias et al. (2016, p. 262) o objetivo principal é que durante a aplicabilidade do progtama seja possível a construção de uma estrutura que garanta a formação integral dos estudantes de rede pública inseridos na Educação Básica por meio de ações que interferem diretamente na qualidade de vida desses indivíduos e de suas famílias, porém, de uma forma integrada, articulando as ações escolares para tratar da saúde e educação com a participação do Sistema de Educação e o Sistema Único de Saúde, dos estudantes, pais, comunidade escolar e sociedade geral (CARVALHO, 2015).

Esta articulação apresenta-se como um desafio, pois, segundo Fontenele, Souza et al. (2017) ela acompanha a necessidade de sensibilização e fortalecimento das relações entre os profissionais da saúde, educação, assistência social e outros, sobre sua rede de apoio básico, de referência e territorialização.

Este tipo de trabalho articulado e intersetorial enfrenta muitos desafios, como por exemplo: a quantidade de profissionais disponibilizada, muitas vezes em quantidade insuficiente; a priorização dos resultados por parte dos gestores; a discussão de determinados temas com estudantes adolescentes, bem como a proximidade destes temas com este público. Por isto, todos os envolvidos com o PSE, sejam escola, saúde, assistência social ou famílias, precisam agir sem medir esforços, no sentido de garantir que as atividades possibilitem uma aproximação e a criação de vínculos necessários para o desenvolvimento das ações de promoção e prevenção à saúde dos adolescentes (MAZETTO, et al., 2019)

Ações escolares, programas e políticas públicas, como o PSE, precisam ser monitorados e avaliados regularmente para que possam ser alterados quando necessário, no decorrer de sua execução, garantindo que os objetivos sejam alcançados e considerando o perfil dos envolvidos, sua participação e mobilização. Esta retomada constante das ações do programa possibilita que estas possam ser repensadas e construídas coletivamente, com a participação ativa dos envolvidos, uma ação conjunta em que os sucessos, fracassos e dúvidas são compartilhados, retomados e reconduzidos na ação, reflexão e ação (BATISTA, MONDINI, JAIME, 2017). 
A participação coletiva e ativa dos envolvidos com o Programa, numa gestão democrático-participativa, possibilita vislumbrar uma escola que tem como objetivo a formação de sujeitos críticos, capazes de exercer a cidadania de forma consciente, com informações, habilidades e competências que os possibilitem agir em defesa da vida, buscando uma melhor qualidade desta. Esta escola e suas ações, precisam ser compreendidas as equipes de Saúde da Família (ESF) em suas estratégias de cuidado, articulando ambos os Programas (BRASIL, 20II).

\section{As IST's como ação do PSE - Programa Saúde na Escola}

$\mathrm{Na}$ adolescência os jovens passam por inúmeras transformações biológicas, emocionais, sociais, fisiológicas e psicológicas. Deixam de ser crianças, mas ainda não são adultos. Neste período repleto de descobertas emocionais e afetivas os jovens estão num processo de autoconhecimento e conhecimento do outro. Surge o interesse sexual por outras pessoas, as primeiras experiências, a descoberta pela sexualidade. Entretanto, este período tão cheio de novidades, se estiver permeado pela falta de informação sobre a educação sexual, pode tornar os adolescentes mais vulneráveis e suscetíveis a comportamentos de risco para sua saúde e daqueles com os quais se relacionam (LIMA, FERREIRA JÚNIOR, MESSIAS, 2017).

Os jovens, pela falta de informação e pelo período de transição em que se encontram (entre a infância e a vida adulta), podem acreditar que são imunes, que sabem tudo o que precisariam sobre sexo, por não terem tido informações e orientações necessárias no início de sua vida sexual ativa, acabando por exercê-la sem nenhuma prevenção, expondo-se a infecções sexualmente transmissíveis (IST) e gravidez não desejada. Se a orientação adequada não advém dos familiares responsáveis, ou da educação escolar, estes jovens tornam-se vulneráveis, um grupo de risco para ISTs (DIAS, et al., 20I0).

Esta vulnerabilidade dos jovens é endossada pelos índices de estatísticas que apontam para o fato de que um em cada três jovens, com idade entre io e 24 anos, são portadores de Infecções sexualmente transmissíveis, em específico, AIDS. Para Ciriaco (2019) a incidência de Infecções Sexualmente Transmissíveis (IST) é um problema de saúde pública mundial, e, sendo este índice elevado entre os jovens, faz-se necessário um investimento em programas 
de educação sexual, programas de prevenção e promoção à saúde, com vistas a melhora deste quadro.

No Brasil, estes elevados índices de IST entre a jovens ratificam importantes intervenções no campo da saúde e educação sexual e reprodutiva, como dito anteriormente, tanto no que tange a prevenção quanto a promoção da saúde, como no da assistência propriamente dita (BRASIL, 2006).

Destarte, no ano dezo07, o Programa Saúde e Prevenção nas Escolas (SPE) passa a integrar o Componente II do Programa Saúde na Escola (PSE), "Promoção da Saúde e Prevenção de Doenças e agravos”, sendo uma das principais estratégias para desenvolver nas escolas ações sobre educação sexual; saúde reprodutiva; uso de drogas lícitas e ilícitas; prevenção de infecções sexualmente transmissíveis e de hepatites virais; alimentação saudável; prática corporal; cultura da paz; saúde mental; saúde ambiental e desenvolvimento sustentável. (BRASIL, 20II)

Em 2008, o Programa Saúde na Escola (PSE) foi implementado pelo Ministério da Saúde, com o objetivo, como dito anteriormente, de articular ações da saúde na escola, possibilitando que os estudantes da Educação Básica, os jovens brasileiros, tenham acesso a informações e ações preventivas relacionadas à sua saúde e de seus familiares, promovendo uma melhor qualidade de vida Nesse sentido, como o PSE visa esta integração entre os setores da educação e saúde, os profissionais de ambos devem ser aliados, trabalhando em conjunto a temática sexualidade nas escolas, bem como assuntos transversais relacionados a esta (SILVA, et al., 2016).

Todas as ações de promoção da saúde e prevenção de doenças e agravos que fazem parte do Componente II do PSE, visam nas escolas, com a colaboração dos profissionais da saúde, educação, assistência social e parceiros afins, garantir a todos os educandos a oportunidade de fazer escolhas mais saudáveis, éticas e responsáveis e de serem protagonistas do processo de produção de sua própria saúde. (SÁ, 2020).

\section{As DST - Doenças Sexualmente Transmissíveis e as Infecções sexualmente transmissíveis - IST na adolescência}

No ano de 200I o termo Doenças Sexualmente Transmissíveis (DST) foi substituído por Infecções Sexualmente Transmissíveis (IST) pela Organização Mundial da Saúde 
(OMS), pois, a terminologia “doenças” agrega o sentido de sintomas de enfermidade e, muitas infecções são assintomáticas e precisam ser consideradas por serem tão graves quanto aquelas que apresentam sintomas evidentes. Segundo Rodrigues (2010), conhece-se hoje mais de 20 agentes infecciosos susceptíveis de transmissão por relações sexuais (bactérias, parasitas, fungos ou leveduras e vírus) e muitos não apresentam sintomas evidentes, principalmente no início da infecção.

Essas infecções sexualmente transmissíveis, em sua grande maioria, manifestam-se na região genital ou em outras partes do corpo, mas, como dito, podem não apresentar sintomas aparentes. Por esta razão, muitas pessoas tendem a agir como disseminadores. Atrelado à falta de ciência de estarem portando alguma IST, estão práticas sexuais de risco, como a troca frequente de parceiros, ausência de uso de preservativos e outros métodos preventivos, contribuindo para a propagação das infecções e aumento dos índices de incidência das IST (SANTOS, RODRIGUES, CARNEIRO, 2009).

Segundo a OMS, os índices relacionados às IST vêm aumentando a cada ano, o que aumenta consideravelmente o risco de mais pessoas se contaminarem com infecções graves que resultam em mortes, nascimentos prematuros, entre outros problemas correlacionados. Os dados estimam mais de I milhão de casos novos de IST por dia, no mundo; cerca de 357 milhões de novas infecções ao ano, entre sífilis, tricomoníase, gonorreia e clamídia. Infecções por sífilis resultam em 300 mil mortes fetais e neonatais ao ano no mundo todo, colocando 215 mil crianças em risco de nascimento e morte prematura (BRASIL, 2017).

\section{Vírus da Imunodeficiência Humanada na adolescência}

A adolescência é uma fase da vida de mudanças e aprendizado, onde o individuo passa por novas experiências que podem gerar consequências por toda sua existência. Por isso, é necessário utilizar esse momento que os jovens estão em aberto às mudanças comportamentais para intensificar a educação em saúde e sexual. A implantação de ações de educação sexual entre as crianças e adolescentes é importante, pois os estudos relatam que a média da primeira relação sexual no Brasil, é a entre a faixa etária de 14 a 15 anos, e os fatores que influencia o HIV é a pobreza, a violência, exploração sexual e dificuldade aos determinantes de saúde. (CAMARGO e BOTELHO; 2007) 
O HIV é uma sigla para vírus da imunodeficiência humana, $\mathrm{O}$ vírus que pode levar à síndrome da imunodeficiência adquirida (AIDS). Os agentes causadores são os retrovírus: HIV-I e HIV-2; Além da via sexual (esperma e secreção vaginal), o vírus pode ser transmitido pelo sangue (através da gestação, parto, uso de drogas injetáveis, transfusões e transplantes) e pelo leite materno. A partir do momento em que a pessoa é infectada, ela tem a capacidade de transmitir o HIV. A presença de outras Infecções Sexualmente Transmissíveis (IST) favorecem a transmissão do HIV (UFPI, 2020).

A infecção pelo HIV e a aids fazem parte da Lista Nacional de Notificação Compulsória de doenças (Portaria de Consolidação no 4, de 28 de setembro de 2017), sendo que a aids é de notificação compulsória desde 1986; a infeção pelo HIV em gestantes, desde 200o; e a infecção pelo HIV, desde 2014. Assim, na ocorrência de casos de infecção pelo HIV ou de aids, estes devem ser reportados às autoridades de saúde (MINISTÉRIO DA SAÚDE, 2020).

A Aids é a DST mais recente que se conhece e a única de notificação compulsória. Identificada no início da década de 8o, constitui-se num expressivo problema de saúde pública mundial. As pessoas portadoras do $\mathrm{HIV} /$ aids são vítimas de implicações físicas e biológicas devastadoras, bem como sociais, espirituais, psicoemocionais, e enfrentam sobretudo, o caráter estigmatizante de uma infecção que envolve a dimensão comportamental do indivíduo. A epidemia afeta todos os grupos sociais com predominância da faixa etária de 20 a 39 anos, impondo diversos desafios à humanidade. Constitui-se objeto de constantes estudos e esforços, que buscam a prevenção e o controle da infecção/ doença, melhor assistência aos portadores e a descoberta de tratamentos e vacinas eficazes (REIS e GIR, 2002)

A relação entre adolescentes e Aids não é nova, e demonstra que o seu enfrentamento ainda é um grande desafio em nossa sociedade. $O$ primeiro caso de Aids em jovens brasileiros data de 1982 e o seu número, desde então, vem crescendo consideravelmente, levando a índices epidemiológicos alarmantes (ARAÚJO, PACHECO, et al., 2013).

A população de adolescentes e jovens possui vulnerabilidade à infecção pelo vírus do HIV, uma vez que nesse período acontece a iniciação sexual desses indivíduos ou contato com vias de transmissão por meio de perfuro cortantes (drogas injetáveis), oportunizando a falta de prevenção e contágio pelo vírus. Em adolescentes a transmissão pode ser dividida em 
dois grupos: os infectados pelo HIV pela transmissão vertical e os infectados pela transmissão horizontal, os que se infectaram por relações sexuais desprotegidas e uso de drogas injetáveis sem os devidos cuidados. (CARNEIRO, MONTEIRO, et al., 2019).

O sexo sem uso do preservativo, o desconhecimento dos riscos, a desinformação e a falta de programas de prevenção na maioria das escolas brasileiras são fatores que favorecem o aumento do número de adolescentes portadores de HIV (ALMEIDA, CORRÊA, et al., 2017).

Mesmo com todas as informações e disponibilização do preservativo feminino e masculino, observa-se que o uso do preservativo entre os jovens deixa desejar. (TEIXEIRA, et al, 2006)

Para os jovens que vivem com HIV/aids, a formação da identidade ultrapassa as descobertas e transformações da adolescência em geral, já que o adolescente tem de se deparar com seu diagnóstico e conviver com essa doença que, além de crônica, é permeada por preconceito, medo e incertezas quanto ao futuro SPINARDI, MACHADO, et al., 2008).

\section{O papel da educação e as ações de prevenção das IST}

A escola é considerada um local onde os adolescentes passam a maior parte do seu dia, que inicia a relação de amizade, namoro e interesse sexual. Com isso, é necessário considerar a escola como um espaço de aprendizado, sendo importante buscar estratégias para os professores de Ciências e Biologia ensinarem sobre os temas específicos, como a prevenção das IST, relação sexual e o uso adequado do preservativo. A utilização de roda de conversa, grupos interativos e metodologia lúdica no ensinamento, proporciona o esclarecimento de dúvida entre os envolvidos. (MONTEIRO, et al, 2019)

Além dos aspectos epidemiológicos, a prevenção das IST/aids envolve, sobretudo, questões socioculturais e psicoafetivas. As ações de prevenção e assistência devem levar em conta como homens e mulheres são socializados, como se relacionam e de que forma exercem sua sexualidade. Portanto, as diretrizes de integralidade, de sensibilidade sociocultural e de viabilidade econômica e financeira determinam a perspectiva de que ações de prevenção (BRASIL, EXECUTIVA e AIDS., 2003) 
Conhecer o perfil da educação sexual das adolescentes é de fundamental importância para se pensar em formas de intervenção educacional nessa população, permitindo um trabalho de promoção da saúde, esclarecimento de dúvidas, ruptura de barreiras, preconceitos, mitos e verdades sobre DST, gravidez e métodos anticoncepcionais. A ação deve ser conjunta entre as famílias, as escolas e a comunidade médica. Com o conhecimento desta realidade, torna-se mais fácil levar informação e esclarecimento a essas mulheres, visto que poderá ser feita uma abordagem direta, enfatizando os principais pontos a elas inerentes (FERREIRA, MIRANDA e BARONI, 20I6).

As atividades de prevenção cuja realização está prevista nos serviços de atenção básica podem ser agrupadas em: oferta de testagem voluntária e aconselhamento para população geral e para gestantes; disponibilização de preservativos; inclusão, nos serviços, dos segmentos populacionais mais vulneráveis; assistência às DST; orientações aos usuários em atividades cotidianamente realizadas nos serviços. Devem ser guiadas pelos princípios éticos que sustentam o componente de prevenção do PN DST/AIDS: respeito à diversidade sexual, à vivência da sexualidade e ao uso de drogas, com abordagens baseadas nos princípios de direitos humanos, participação social e na noção de vulnerabilidade, atentas às dimensões subjetivas da prevenção $e$ aos contextos estruturantes da vida das pessoas e dos grupos (FERRAZ e NEMES, 2009, p. 242).

A interação dos professores da rede de ensino com a equipe de atenção básica a saúde, é essencial para levar o conhecimento sobre saúde para os educandos. O programa Saúde na escola é considerado como facilitador para a comunicação desses atores.

\section{O papel dos Gestores e saúde pública}

O processo de formação dos gestores e das equipes de educação e de saúde que atuam no PSE é um compromisso das três esferas de governo e deve ser trabalhado de maneira contínua e permanente, sendo fundamental no enfrentamento do desafio da prática intersetorial e da produção de educação e de saúde integral (BRASIL, 2015)

As três esferas de governo, Municipal, Estadual e Distrito Federal, atuam na organização do Programa Saúde na Escola, no âmbito municipal o Grupo Trabalho Intersetorial, tem a responsabilidade de planejar o PSE. Esse grupo possui representantes da secretária de saúde e educação, e representante de outros órgãos ou instituições, como por exemplo, representante do Conselho Municipal de Saúde. (FERREIRA, et al, 2014)

No entendimento do Departamento de DST, AIDS e Hepatites Virais do Ministério da Saúde, para o aprimoramento da gestão devem ser consideradas como questões 
transversais as estratégias que possibilitem, entre outras coisas, o desenvolvimento da capacidade de planejamento, implementação, monitoramento e avaliação dos programas governamentais e das ações da sociedade civil, bem como uma gestão e financiamento por resultados e aprimoramento da governança. Com isso se torna fundamental que estas questões sejam discutidas e analisadas num processo participativo e solidário para o fortalecimento dos pactos interfederativos no âmbito da saúde e para a exequibilidade das ações (MOURA e LEMOS, 2020)

\section{Comunidade Escolar e a Saúde}

É necessário construir um conhecimento crítico dos adolescentes em relação a sua saúde, favorecer a eles o empoderamento de cuidar de si próprio, os responsabilizando de manter sua saúde e se prevenir contra as infecções sexualmente transmissíveis e de uma gravidez indesejada. Mas para que isso ocorra, é necessário à escola implantar essas práticas educativas em seus planos de ensino, enfatizar a temática sexualidade, derrubando conflitos que existe entre os adolescentes quando se trata desse assunto, pois muitos só recebem informações pelos meios de comunicação, pela mídia, amigos e vizinhos, sendo que em muitos casos são repassadas erroneamente, confundido esses adolescentes em relação à sexualidade e como realizar um sexo seguro, sendo que grande parte deles não recebem em casa uma orientação sexual dos pais, pois muitos ainda não conseguem conversa com seus filhos, principalmente quando e filha mulher, no qual a palavra conservadora, ainda é muito importante para algumas famílias, deixando a responsabilidade para a escola, que deve conversar e orientar esses adolescentes, dessa forma, promovendo um bem estar na sua vida sexual atual ou futura (COSTA, LINS, et al., 2013)

Observa-se que a saúde e educação são constantemente evocadas quando a questão gira em torno das condições de vida. A interação entre elas, independentemente de onde ocorre - escola ou serviço de saúde - constitui um caminho importante para a conquista da qualidade de vida. A construção de práticas pedagógicas relacionadas a essa interação é um grande desafio frente às demandas que as escolas enfrentam. (CARVALHO, 2015)

A escola tem representado um importante local para o encontro entre saúde e educação abrigando amplas possibilidades de iniciativas tais como: ações de diagnóstico clínico e/ou social estratégias de triagem e/ou encaminhamento aos serviços de saúde 
especializados ou de atenção básica; atividades de educação em saúde e promoção da saúde. (CASEMIRO, FONSECA e SECCO, 2014)

Para Souza et al (2017, p.1786) o funcionamento e o andamento do PSE - Programa Saúde na Escola depende da participação da família e da comunidade durante todo o processo de construção e aplicabilidade do projeto, tendo como diretrizes apoiadoras as políticas intersetoriais, destacando e tonando possível visualizar os fatores que tem maior interferência na saúde dos indivíduo e/ou coletivo, colocando em situação de vulnerabilidade, ao mesmo tempo é importante traçar estratégias conjuntas para superar os problemas e as adversidades.

Contudo, é importante destacar que não basta abrir espaço para se promover saúde, mas desenvolver nos usuários a importância sobre a corresponsabilidade nessas práticas, sendo a participação dos estudantes na mobilização, capacitação e desenvolvimento de aprendizagem de habilidades individuais e sociais para lidar com os processos de saúdedoença, imprescindíveis para efetivação dessas ações (MACHADO, GUBERT, et al., 2015

\section{CONSIDERAÇÕES FINAIS}

Está trabalho teve como finalidade a abordagem da literaturas sobre o Programa Saúde na Escola, integrado a dois elementos primordiais para o estudo, sendo as IST/AIDS e a prevenção de doenças, analisando como é o desempenho do programa e sua efetividade no cotidiano escolar.

Durante a análise do referencial teórico foi observado um número significativo de artigos que abordam os descritores apresentados e após a consolidado e leitura dos mesmos identificou-se que a temática IST/AIDS tem um grande significado na vida escolar e que o Programa Saúde na Escola aborda a comunidade, educando, educadores e diversos atores que estão ligados direta e/ou indiretamente a escola.

Para além, a revisão de literatura proporcionou expressar o comportamento dos diversos atores envolvidos no PSE, além de trazer a discussão sobre as IST/AIDS levando em considerações os estudos que analisavam a aplicabilidade do projeto nas escolas, trazendo para a discussão a importância de atuar com ações de prevenção e promoção no dia-a-dia da vida academia.

Por meio desse artigo, fez-se possível identificar a importância de trabalhar estratégias para a educação e promoção em saúde entre os jovens e adolescentes que fazem parte das 
escolas brasileira. Identificou-se que existe uma variedade de artigos relacionados ao Programa Saúde na Escola trazendo a luz diversas formas de aplicabilidade da temática IST/AIDS junto aos educandos, comunidade e demais atores, porém faz-se necessário ainda ferramentas de aperfeiçoamento garantindo ainda maior alcance do tema e automaticamente minimização dos problemas de saúde dos indivíduos.

É necessário entender que as mudanças na visão dos profissionais da educação no ensinar sobre a sexualidade e educação sexual principalmente com a atuação do PSE, tem o intuito de promover um desenvolvimento dos educandos tornando-os responsáveis pelos seus atos.

Enfim, ressalta-se que o Programa Saúde na Escola tendo como foco a ação de prevenção das IST/AIDS ainda encontra grandes desafios para sua efetivação, mais em contrapeso é de extrema importância na garantia da qualidade de vida dos educandos e comunidade.

\section{REFERÊNCIAS}

Alavarse, G. M. A.; CARVAlho, M. D. de. B. Álcool e adolescência: o perfil de consumidores de um município do norte do Paraná. Esc Anna Nery Rev Enferm, v.ro, n.3, p.408-416, 2006.

ALMEIDA, R. A. A. S., et al. Conhecimento de adolescentes relacionados às doenças sexualmente transmissíveis e gravidez. Rev. Bras. Enfer. v. 70, n. 5. Set./Out., 2017. Disponível em: https://www.scielo.br/j/reben/a/p4gD43L6gJhMZv3yGkRfvnM/abstract/?lang=pt . Acesso em 04 nov. 2021.

ARAÚJO, T. M. E. de. (coord.) Cartilha Infecções Sexualmente Transmissíveis (IST): IST, prevenção e sexualidade. Teresina-PI, mai. 2020. Disponível em: https://ufpi.br/arquivos_download/arquivos/prex/publicacoes-daextensao/Cartilha_Infeccoes_Sexualmente_Transmissiveis_IST_compressed20200610132403.p df. Acesso em: 05 nov. 2021.

ATAliBA, P.; MOURÃO, L. Avaliação de impacto do Programa Saúde nas Escolas. Psicologia Escolar e Educacional. v. 22, n. I. Abr. 2018. Disponível em: https://www.scielo.br/j/pee/a/jMtgDVfwpmZDVCSBMYnBpcn/?lang=pt. Acesso em o4 nov. 2021. 
BATISTA, M. A.; MONDINI, L.; JAIME, P. C. Ações do Programa Saúde na Escola e da alimentação escolar na prevenção do excesso de peso infantil: experiência no município de Itapevi, São Paulo, Brasil, 2014. Epidemiol. Serv. Saúde, v. 26, n. 3, 569-578, jul./set., 2017.

BRASIL. Ministério da Saúde (MEC). Caderno do gestor do PSE. Brasília: Ministério da Saúde, 2015.

BRASIL. Secretaria de Vigilância em Saúde. Boletim Epidemiológico. Ministério da Saúde, $47,2017$.

BRASIL. Secretaria de Atenção à Saúde. Departamento de Ações Programáticas Estratégicas. Marco teórico e referencial: saúde sexual e saúde reprodutiva de adolescentes e jovens. Brasília: Ministério da Saúde, 2006.

BRASIL. Ministério da Saúde. Secretaria de Atenção à Saúde. Departamento de Atenção Básica. Instrutivo PSE. Brasília: Ministério da Saúde, 2oIr.

BRASIL. Ministério da Saúde. HIV/AIDS - 2020: Boletim Epidemiológico, p. 68, 2020.

BRASIL. Ministério da Saúde. Política e diretrizes de prevenção das DST/aids entre mulheres. (MS, Ed.) Brasília: Ministério da Saúde, 2003.

CARNEIRO, R. R., et al. Qualidade de vida de adolescentes e jovens vivendo com HIV/AIDS: uma revisa integrativa. Temas em Saúde, v. 19, n. 5, 522-541, 2019.

CARVALHO, F. F. A saúde vai à escola: a promoção da saúde em práticas pedagógicas. Physis Revista de Saúde Coletiva, v. 25, n. 4, 1227-1227, 2015.

CASEMIRO, J. P.; FONSECA, A. B.; SECCO, F. V. Promover saúde na escola: reflexões a partir de uma revisão sobre saúde escolar na América Latina. Ciênc. saúde coletiva, v. 19, n. 3, 829-840, mar. 2014.

CAVAlCANTI, P. B.; LUCENA, C. M.; LUCENA, P. L. Programa Saúde na Escola: interpelações sobre ações de educação e saúde no Brasil. Texto \& Contextos, v. I4, n. 2, 387402, ago./ dez. 2015.

CHIARI, A. G. et al.. Rede intersetorial do Programa Saúde na Escola: sujeito, percepções e práticas. Cadernos de Saúde Pública, v. 34, n. 5, 2018. Disponível em: https://www.scielo.br/j/csp/a/d9GHPC 4 rRF9WJKQxyqmbZCG/abstract/?lang=pt. Acesso em 04 nov. 2021.

COSTA, A. J., et al. Vulnerabilidade de adolescentes escolares às DST/HIV, em Imperatriz-Maranhão. Rev Gaúcha Enferm, v. 34, n. 3, 179-186, 2013. Disponível em: https://www.scielo.br/j/rgenf/a/Wd7WwsPZJ 47 BjWj4bkVFq3p/?lang=pt\&format=pdf. Acesso em 04 nov. 2021. 
DIAS, F. A., et al. Riscos e vulnerabilidades relacionados à sexualidade na adolescência. Rev. enferm., v. $18, \quad n . \quad 3,456-461$, jul./ set. 2oro. Disponível em: https://www.researchgate.net/publication/317458570_Riscos_e_vulnerabilidades_relacionados _a_sexualidade_na_adolescencia. Acesso em 04 nov. 202I.

FERRAZ, D. S.; NEMES, M. B. A avaliação da implantação de atividades de prevenção das DST/AIDS na atenção básica: um estudo de caso na Região Metropolitana de São Paulo, Brasil. Cad. Saúde Pública, 240-250, 2009.

FERREIRA, J. T.; MIRANDA, T.; BARONI, A. R. Conhecimento sobre as DST entre adolescentes escolares em Vespasiano, Minas Gerais. Adolesc. Saúde, v. 13, 51-59, set., 2016.

FONTENELE, R. M.; SOUSA, A. I. et al. Construção e validação participativa do modelo lógico do Programa Saúde na Escola. Saúde Debate, v. 4I(Especial), 167-179, mar. 2017.

KÖPTCKE, L. S.; PADRÃO, M. A.; PEREIRA, F. M. A importância da formação continuada para a gestão intersetorial no Programa Saúde na Escola. Com. Ciência Saúde, $27(3), 211-222,2016$.

LIMA, K. S.; FERREIRA JÚNIOR, M. F.; MESSIAS, C. O. Prevenção às IST/AIDS na educação de adolescentes no ambiente escolar: uma visão sobre os desafios da escola e da família. Revista Querubim, v. 03, I0-16, 2017.

LOPES, A. R.; CIPRIANO, J. A.; ALMEIDA, L. S. Docência e ansiedade: a ampliação do PSE como medida preventiva na saúde mental do professor. Joao Pessoa: CONEDU, 2020.

LOPES, I. E.; NOGUEIRA, J. A.; ROCHA, D. G. Eixos de ação do Programa Saúde na Escola e Promoção da Saúde: revisão integrativa. Saúde Debate, v. 42, 773-789, Jul./Set., 2018.

MACHADO, Maria de Fátima Antero Sousa et al. Programa saúde na escola: estratégia promotora de saúde na atenção básica no Brasil. J. Hum. Desenvolvimento de crescimento, São Paulo, v. 25, n. 3, pág. 307-312, 2015. Disponível em http://pepsic.bvsalud.org/scielo.php?script=sci_arttext\&pid=Soro4I2822015000300oog\&lng=pt\&nrm=iso . Acesso em 04 nov. 2021.

MARINHO, M. B., et al. Programa saúde na escola: dos processos formativos aos cenários de práticas. J Hum Growth Dev, v. 28, n. 2, 175 - 182, 2018. Disponível em: https://www.revistas.usp.br/jhgd/article/view/r47219. Acesso em 05 nov. 2021.

MAZETTO, D. F., et al. Programa saúde na escola: possibilidades e desafios na perspectiva da residência multiprofissional em saúde. Revista Família, Ciclos de Vida e Saúde no Contexto Social, v. 7, n. 2, 256-262, 2019.

MOURA, L. N.; LEMOS, S. A.. Avaliação das ações de um programa de DST/AIDS e Hepatites virais: percepção dos gestores. Revista Médica de Minas Gerais, v. 30, 2020. 
PACHECO, Carolina Costa. Prevenção das DST/Aids e sexualidade: perguntas de adolescentes no município de Maricá/RJ. Enfermagem Brasil, v. I2 n. 4. Jul./Ago. 2013. Disponível

em: https://www.portalatlanticaeditora.com.br/index.php/enfermagembrasil/article/view/3757. Acesso em 04 nov. 2021.

REIS, R. K.; GIR, E.. Caracterização da produção científica sobre doenças sexualmente transmissíveis e HIV/AIDS publicados em periódicos de enfermagem no Brasil. Rev Esc Enferm, v. 36, n. 4, 376-85, 2002.

RODRIGUES, M. J.. Doenças Sexualmente Transmissíveis (DST) na Adolescência. Nascer e Crescer, v. XiX, n.3, 2010.

SÁ, M. C. (2020). Promoção da saúde e ações intersetoriais: foco no Programa Saúde na Escola. Caderno de Saúde Pública, v. 36, n. 3, 2020. Disponível em. https://www.researchgate.net/publication/340109883_Promocao_da_saude_e_acoes_intersetor iais_foco_no_Programa_Saude_na_Escola. Acesso em 05 nov. 2021.

SANTOS, R. A.; MEZZAROBA, C.. Programa Saúde na Escola e sua relação com a Educação Física: uma análise documental. Praxia, v. I, n. 4, 71- 89, 2013.

SANTOS, S. J.; RODRIGUES, J. A.; CARNEIRO, W. S. Doenças Sexualmente Transmissíveis: conhecimento de alunos do ensino médio. DST-J, v. 2I, n. 2, 63-68, 2009.

SANTOS, T. F.; SILVA, J. F.; NASCIMENTO, M. d. Programa Saúde na Escola: contribuição e limites na perspectiva dos professores. UNIT, 2016.

SILVA, S. C. et al. Discutindo sexualidade/IST no contexto escolar: práticas de professores de escolas públicas. Revista de Enfermagem, v. Io, 4295-303, nov. 2016.

SILVEIRA, C. C.; MEYER, D. E.; FÉLIX, J. A generificação da intersetorialidade no Programa Saúde na Escola. Rev. Bras. Estud. Pedagog., v. Ioo, n. 255, 423-442, mai./ago. 2019.

SPINARDI, J. R. et al. Adolescer com HIV: saber, conhecer e conviver. Adolescência \& Saúde, v. 5, n. 2, 7-I4, jul. 2008.

VIEIRA, L. S.; BELISÁRIO, S. A. Intersetorialidade na promoção da saúde escolar: um estudo do Programa Saúde na Escola. Saúde debate, v. 45, n. 4, 120-133, dez. 2018.

VIEIRA, L. S.; SAPORETTI, G. M.; BELISÁRIO, S. A. Programa Saúde na Escola: marcos jurídicos e institucionais. Rev Med Minas Gerais, v. 26, n. 8, 38I-387, 2016. 